CONNOTAS. REVISTA DE CRítica Y TEORÍA LITERARIAS/Núm. 14-15/2014-2015

\title{
El quehacer historiográfico de los fantasmas. Aproximaciones a Doña Inés contra el olvido de Ana Teresa Torres
}

\author{
María Carrillo* \\ Una cabera humana viene lenta desde el olvido \\ Tenso se detiene el aire \\ Vienen lentas sus miradas \\ Un lirio trae la noche a cuestas \\ Cómo pesa el olvido...
}

E. A. Westphalen, Las insulas extrañas.

Resumen:

La novela de Ana Teresa Torres publicada en 1992, Doña Inés contra el olvido, invierte los papeles de la narración sumándose a la corriente de la nueva novela histórica. Aquí la historia de los vivos la cuentan los muertos. El fantasma de Doña Inés Villegas y Solórzano narra tres siglos de la historia de Venezuela al intentar resolver un litigio por sus tierras perdidas en 1663. Con una mirada que oscila entre el pasado y el presente, la novela retrata la situación específica de este país dentro del marco de la posmodernidad. Se rompen las fronteras entre la realidad y el delirio, el mundo deja de ser legible y el sujeto individual se desvanece en un sujeto colectivo. El fantasma de Doña Inés se enfrenta a su disolución en su circunstancia. Hay dos salidas posibles: el refugio en el pasado, reinventándolo, o la fuga del presente, relativizándolo.

${ }^{*}$ El Colegio de San Luis. 
Se propone a continuación un estudio que ponga en relieve algunos rasgos de esta obra en relación con la narrativa de la Nueva Novela Histórica. Se abordará la relación entre el discurso privado y el oficial, la capacidad de olvido y de memoria, la autoconciencia en la construcción de la propia historia y la vOz femenina en el discurso histórico contemporáneo.

Palabras clave:

Ficción, historia, discurso, nueva novela histórica.

En su libro de 1978, La escritura de la historia, Michel de Certeau entendió la operación historiográfica como un ritual de entierro en el cual la escritura se apropia de los muertos, fantasmas del pasado, para llevarlos a la dimensión simbólica que lanza la posibilidad de abrir en el presente el espacio de lo no resuelto, de lo que queda por hacer. Enterrar a los muertos es, entonces, reasignar un lugar a los vivos. ${ }^{1}$ No dista esta imagen, tal vez demasiado aventurada, de las reflexiones de Paul Ricoeur en La memoria, la historia, el olvido, publicado en el 2000. En la medida que toda situación se vuelve pasado en el momento de su escritura, el historiador siempre habla de muertos. Incluso si la historia del tiempo presente interpela a los vivos, lo hace en "calidad de testigos supervivientes a acontecimientos que están cayendo en el olvido del pasado" (Ricoeur 471), afirma Ricoeur sumergiéndose más a fondo en la pregunta por la temporalidad en la historia. Sin mayores cuestionamientos, se puede ver en esta manera de asumir el tiempo la posición distintiva del historiador que voltea hacia los hechos como situaciones ya dadas que bien pueden revalorarse, siempre y cuando se acepte su condición irreversible.

${ }^{1}$ Véase especialmente el apartado "El lugar del muerto y el lugar del lector", pp. 116-18. 


\section{Propuesta historiográfica invertida}

¿Qué pasa si en un texto se invierten los papeles y los fantasmas vuelven para contar la historia de los vivos? Con todo y la duda sobre la hibridación entre ficción e historia entraríamos sin más en el plano de la narración literaria. Tal es el caso de la novela de Ana Teresa Torres, Doña Inés contra el olvido, publicada en 1992, ${ }^{2}$ donde la voz más importante corre a cargo del fantasma que narra tres siglos de la historia de Venezuela: doña Inés Villegas y Solórzano, nieta del conquistador español don Pedro de Villegas. El móvil de la novela es el litigio que doña Inés entabló con su paje y liberto Juan del Rosario por la posesión de las tierras en el valle de Curiepe que le fueron expropiadas en 1663.

Como hace ver Cynthia Tompkins en su artículo "La re-escritura de la historia en Doña Inés contra el olvido de Ana Teresa Torres", hay una asidua documentación historiográfica que precede la escritura de esta novela. Cynthia Tompkins, tras una plática con la autora, da a conocer las fuentes que dieron origen a Doña Inés contra el olvido y se dedica a cotejar la información de estos textos historiográficos, llegando a la conclusión de que, además de cambiar el nombre doña Catalina Villegas por doña Inés, no hay mayores discrepancias, y, lo que más interesa, las ambigüedades de la narración guardan relación con los documentos consultados. ${ }^{3}$

\footnotetext{
${ }^{2}$ Ana Teresa Torres nació en Caracas en 1945. Su primera novela El exilio del tiempo se publicó en 1990. En 1992 apareció Retrato frente al mar y Doña Inés contra el olvido; en este año también publicó tres ensayos psicoanalíticos: Mujer y sexualidad, La mujer y la perversión y Elegir la neurosis. Ana Teresa Torres lleva a la par su actividad como narradora y como psicoanalista. No creo que esté por demás tener presentes algunos principios de psicoanálisis al acercarse a su obra.

${ }^{3}$ La entrevista a Ana Teresa Torres fue realizada en Caracas el 4 de Agosto de 1994; en ella la autora menciona los dos textos más importantes para su novela: Apuntes para la historia colonial de Barlovento de Lucas Guillermo Castillo Lara (Caracas, Biblioteca de la Academia Nacional de la Historia, 1981); y Las tierras de Barlovento del Estado Miranda: Estudio jurídico-parcelario de Carlos González Araujo (Caracas, Editexto, 1987); además de algunos artículos de El Nacional, especialmente uno publicado el jueves 20 de Marzo de 1986, p. 8, "El estado recuperó
} 
La ficción, o lógica fracturada, de la práctica historiográfica, la puesta en duda del discurso histórico oficial, por no hablar de la caída de la noción de verdad histórica, son rasgos que sin duda han llamado la atención de la crítica al enfrentarse con esta novela; pero no terminan aquí las inquietudes que ha despertado la narración del fantasma Doña Inés. Desde las reseñas publicadas aproximadamente un año después de la novela, ${ }^{4}$ la fusión histórico-literaria ha motivado la búsqueda de la filosofía subyacente que Ana Teresa Torres intenta transmitir a sus lectores, en especial a la sociedad venezolana. Para responder a esta pregunta, varios estudios toman el camino de la ideología feminista, o de los estudios de género, viendo en la narración el rescate de figuras olvidadas que no han tenido un papel determinante en la historia nacional. Doña Inés contra el olvido, según este tipo de estudios, se desplaza hacia el ambiente íntimo - la casa, la familia- dominado por la figura femenina, para así reestructurar la historia. ${ }^{5}$ Otra vertiente de la crítica va hacia el descontento como expresión del sentimiento venezolano frente a la caída político-económica de los últimos años. Es muy revelador en este sentido el artículo de Luis Britto García, extraído de su

más de 200 millones de metros cuadrados en Barlovento". También aclara la autora que los episodios de la esclava Daria y la niña Magdalena provienen del acervo popular; el primero de un incidente similar ocurrido durante el terremoto de 1812; el segundo se basa en la anécdota sobre una muñeca, niña-virgen, envuelta para regalo, que fue obsequiada al General Gómez por motivo de su cumpleaños (pp. 103-14, del artículo de C. Tompkins ).

${ }^{4}$ Véanse las reseñas de Bárbara Mujica en la revista Américas, 45: 4 (1993), pp. 61-62; y Cynthia Tompkins en World Literature Today, 67: 2 (1993), p. 337.

${ }^{5}$ Algunos estudios de corte feminista que se interesan por la revaloración de la mujer como medio para la reestructuración de la historia son: Fabiola Franco, "Mujer, historia e identidad en Hispanoamérica: Doña Inés contra el olvido de Ana Teresa Torres", Revista de Literatura Hispanoamericana, 35 (1997), pp. 63-73; Iraida Casique, "La mirada femenina de una historia sin héroes", Texto Crítico, 5: 10 (2002), pp. 75-88; Beatriz González Stephan, "La resistencia de la memoria: una escritura contra el poder del olvido", en Karl Kohut (ed.), Literatura venezolana boy. Historia nacional y presente urbano, Frankfurt-Madrid, Vervuert-Iberoamericana, 1999, pp. 115-26, Actas del Simposio "Literatura venezolana hoy. Historia nacional y presente urbano", Río de Janeiro, del 31 de enero al 3 de febrero de 1996. 
ponencia del Simposio de 1996, "La vitrina rota. Narrativa y crisis en la Venezuela contemporánea”, que marca la situación específica de Venezuela dentro del marco de la posmodernidad. Los venezolanos tienen que enfrentarse a una existencia nacional e individual sin proyecto. Se rompen las fronteras entre la realidad y el delirio, porque el mundo deja de ser legible y el sujeto se desvanece en un sujeto colectivo. El pasado se vuelve el único reino posible cuando la debilidad de la memoria no llama hacia ninguna aspiración atractiva para el futuro. Aparece un ser disuelto en su circunstancia con dos salidas posibles: el refugio en el pasado, reinventándolo, o la fuga del presente, relativizándolo.

En el mismo Simposio, Ana Teresa Torres participó con un texto sobre las relaciones entre la literatura y la situación histórica de Venezuela a finales del siglo XX, en el que hace una revisión desde $1958^{6}$ hasta el presente, determinada por "una erosión de la economía y otros signos de deterioro, tales como el descenso de los niveles de lectura, el colapso de la salud pública, la pérdida de credibilidad en el sistema político y el auge delictivo en todos los estratos sociales"(Torres, "Literatura" 56). Lejos de referirse al concepto de modernidad o posmodernidad, Ana Teresa Torres asume que el escritor es uno con su circunstancia. La dicotomía realidad-fantasía, verosimilitud-imaginación, no puede dejarse al margen de una mirada retrospectiva que muestra en el discurso oficial la legitimación del mundo venezolano como "el mejor de los mundos posibles"(63). La memoria erosionada no ve en el pasado sino dictaduras y opresiones, confunde el signo de los gobiernos con la sociedad misma y con la producción cultural de su época.

Lo pasado siempre olía mal, era lo caduco, lo decadente, lo despreciable. Se ha dicho muchas veces que el venezolano es amnésico; más bien, enseñado a no querer recordar, conducido al desgarramiento simbólico de la memoria, que ha terminado por arrojarlo solo, en medio de una realidad que

\footnotetext{
${ }^{6}$ Año de la caída de la dictadura perezjimenista.
} 
resulta incomprensible, brutal, y en la que debe caminar a ciegas (Idem).

La literatura, entonces, tiene la doble función de crear mundos posibles y rescatar al pasado del discurso oficial. La propuesta estética que se desprende de estas reflexiones niega la literatura como reflejo de la realidad o como campo de ficción.

La realidad y la ficción puras -si es que tales cosas existenson aburridas para el ciudadano de fin de siglo que puede observarlas cotidianamente en la pantalla de televisor o de su PC. La literatura no puede sino sostenerse sobre aquello que la constituye: la capacidad del lenguaje de decir más de lo que dice (60-61).

Tal vez esta sea la clave de lectura en Doña Inés contra el olvido, pues la novela no puede reducirse a un problema metahistórico, ni tampoco a una lucha en contra de la ideología dominante que ha determinado la situación de Venezuela en los últimos años.

Por su construcción, Doña Inés contra el olvido se inscribe dentro del marco de la nueva novela histórica, ${ }^{7}$ pero también comparte importancia con el núcleo que gira en torno a autoras y temas asociados con lo femenino. La escritura de mujeres se ha vuelto un tema de exploración en el presente literario. Y aquí salta la pregunta obligada por sus rasgos distintivos. Carlos Pacheco en "Textos en la frontera: autobiografía, ficción y escritura de mujeres", intenta responder esta pregunta encontrando en el énfasis en la construcción individual de personajes el aspecto que une a los textos escritos por mujeres. Luz Marina Rivas, a su vez, propone algunas categorías que podrían ayudar a encontrar marcas de lo femenino, aclarando que se trata de tendencias y no de rasgos definitorios o

\footnotetext{
${ }^{7}$ Véase el artículo ya citado de Cynthia Tompkins que identifica en Doña Inés contra el olvido todos los elementos que Seymour Menton marca como específicos de la nueva novela histórica en América Latina.
} 
exclusivos de la escritura hecha por mujeres. Está la preferencia por discursos de intimidad, el privilegio de la subjetividad femenina al interior del texto, la contextualización de los sujetos femeninos, las elecciones temáticas, el diálogo con el Otro, y el cuestionamiento de representaciones arquetípicas femeninas. En la figura de doña Inés aparecen todos, pero con el contrapunto de don Heliodoro, la otra voz privilegiada de Ana Teresa Torres. Tal vez lo femenino en la novela esté justo en los saltos del ambiente íntimo a los dominios públicos. Oscilación de interior a exterior, no en el desgaste del que hablaba Simone de Beauvoir, sino en una perspectiva privilegiada que por sus condiciones de vida tiene más puntos de referencia al preguntarse por el pasado. El riesgo de esta afirmación es reducir el valor de Doña Inés contra el olvido a la "sensibilidad" de la autora. No ha de olvidarse que la novela, aun si comparte rasgos con la escritura hecha por mujeres, no agota en ellos su complejidad al abordar temas como la capacidad de olvido y de memoria, las relaciones entre discurso privado y el oficial, la autoconciencia en la construcción de la propia historia, entre otros. En su conjunto, estas aproximaciones dejan ver la aportación de Ana Teresa Torres a un estudio sobre la nueva novela histórica: abrir la pregunta por la mirada histórica para llevarla al discurso íntimo como única posibilidad de saldar cuentas con el pasado.

\section{Estructura narrativa}

Doña Inés contra el olvido tiene un complejo sistema de relaciones que va de los documentos -objetos físicos reales- a la conciencia de su consignación en el tiempo, no sin tocar el problema del olvido y la memoria. Los elementos narrativos que forman el entramado conceptual son: las marcas temporales, las voces del relato y el objetivo de la historia narrada.

El tiempo de la narración abarca desde 1715 hasta 1985, con un claro punto de referencia en el presente. Aun cuando el texto aparece marcado por una cronología divida en tres periodos y estos a su vez en situaciones concretas, fechadas, la temporalidad siempre 
está en relación con el momento actual (1985) marcado en la voz de doña Inés. El discurso tiene valor cuando es pronunciado; la mirada hacia el pasado es relativa al punto de partida de la enunciación.

La voz de doña Inés domina la mayor parte de la novela, pero no se trata de una narración inequívoca. Son determinantes los personajes ausentes, fantasmas que solo ella puede oír: Alejandro Villegas y Juan del Rosario los más importantes. Tal como lo define Bajtín, el diálogo oculto con estos personajes cobra sentido cuando influyen en la voz principal. ${ }^{8}$ En el relato solo aparece rastro de sus palabras en réplicas, consideraciones y preguntas dirigidas a doña Inés. Además se hace evidente a lo largo de la narración la evolución de estos personajes ocultos desde la mirada de doña Inés.

Como ya se dijo, el motor de la novela es la solución del litigio de las tierras del valle de Curiepe. Doña Inés se presenta como un fantasma que ha salido del tiempo para resolver un problema que - poco a poco se descubre- no gira en torno a la posesión material, sino al deterioro de la memoria. La meta es entonces consignar la propia historia, para volver a ser fantasma de papel. En medio de esta meta se encuentran los documentos que prueban o desautorizan la versión de doña Inés. Los documentos, en cuanto objetos carentes de valor en sí mismos, propician diferentes lecturas de la historia. Voces que contradicen la historia de doña Inés, pretendidamente inequívoca, con todo y la visión panorámica que un fantasma puede permitirse. Este fantasma, a pesar de romper las fronteras del tiempo y del espacio, deja en claro la imposibilidad de asir al mundo en su totalidad. La experiencia, por más que extienda su campo de visión, no puede desprenderse de su condición subjetiva. Argumento demostrado en la convergencia de

\footnotetext{
${ }^{8}$ En palabras de Bajtín, cuando aparece un diálogo oculto "el segundo interlocutor está presente invisiblemente, sus palabras no se oyen, pero su huella profunda determina por completo el discurso del primer interlocutor. A pesar de que sólo habla una persona sentimos que se trata de una conversación, y una conversación muy enérgica, puesto que cada palabra presente reacciona entrañablemente al interlocutor invisible, señalando fuera de sí misma, más allá de sus confines, hacia la palabra ajena no pronunciada" (287).
} 
datos provenientes de cartas, memoriales, frases anónimas, marcas de oralidad, etc. ${ }^{9}$

Los recursos narrativos de la novela desembocan en la imagen discursiva que André Gide llamó mise en abyme; es decir, el relato dentro del relato. Al comenzar la lectura de Doña Inés contra el olvido nos encontramos con el título de la primera parte indicado por un periodo temporal, 1715-1835, y luego el título del primer capítulo "Doña Inés entre memoriales (1715-1732)", lo que ya sugiere que se trata de una crónica. Una voz comienza a narrar su historia; la primera frase es: "Mi vida fue atravesar mañanas lentas, días largos que el tiempo recorría despacio..." (Torres, Doña Inés 11); desde este momento se hace evidente el relato de rememoración que seguirá la protagonista. Sin embargo, salta a la vista una contradicción: la narración está en primera persona, y el título aparece asignado por un tercero. Aquí está el juego narrativo más importante de la novela que consiste en juntar el tiempo de la lectura con el de la narración y la escritura. El propósito de doña Inés es consignar su historia y para eso llama a un escribano, que, como vemos en los títulos de los capítulos, tiene la función de editar el texto que le fue dictado. Dice doña Inés: "Los postreros esfuerzos de mi memoria se diluyan en el intento de establecer con ellos una cronología, que venga el escribano y prepare su caja de tinteros, que moje la pluma y levante testimonio de mi memoria" (12). Varias veces, sobre todo al final de los capítulos, doña Inés llamará al escribano para darle órdenes. Así termina la segunda parte: "Anota, escribano: Domingo Sánchez deja saldada su deuda con las mujeres de la casa de San Juan" (164). La autoría al interior de la novela queda dividida entre doña Inés como autor y el escribano como editor, ambos figuras de ficción. El tiempo de estos sujetos de enunciación se invierte cuando, al momento de la lectura, llegan primero los rasgos que anuncian el trabajo del escribano-editor. Se crea un juego de espejos que su-

\footnotetext{
${ }^{9}$ La convergencia de voces es un amplio tema de estudio en esta novela. Lo explora atentamente Luz Marina Rivas en su libro La novela intrabistórica. Tres miradas femeninas de la historia venezolana.
} 
merge la historia de doña Inés dentro del resultado de su proyecto: la crónica terminada. En la tercera parte de la novela, estos juegos metaficcionales se multiplican en la narración de otros personajes. Primero en la narración en que Belén transmite a sus sobrinos la historia familiar de la esclava Daria que salvó a su bisnieta Isabel, única superviviente de la familia durante la emigración a Oriente en la guerra de Independencia. Después el abogado-historiador Don Heliodoro -si bien desde los documentos y no desde el proyecto de doña Inés- hace una recapitulación de la historia del litigio, reproduciendo en miniatura lo que se ha contado en la novela. Dice Don Heliodoro: "Más de una vez me he imaginado a esa vieja mantuana, parada detrás del escribano insuflándole su furia y gritando insultos contra Juan del Rosario, los gobernadores y el mismísimo Rey" (194). La estrategia narrativa del relato dentro del relato se adelanta al futuro incluyéndose en su propio proyecto, ${ }^{10}$ pero esto no queda en la novela como mero rasgo de inquietante metaficción, sino que está en relación con dos aspectos del proceso psicoanalítico: la toma de conciencia del propio discurso y el mecanismo del olvido.

La investigación en psicoanálisis es la del "analizante", o paciente, sobre sí mismo ante un otro, el analista, que tiene la función de hacerlo consciente de su discurso enfrentándolo con sus propias palabras. ${ }^{11}$ La relación es la de una imagen a escala devuelta mediante un espejo, que no la refleja tal cual sino con datos o llamadas a elementos que el analizante no había notado. La puesta en abismo se logra con la interferencia de un otro, pero que pasa desapercibido dando importancia al discurso de quien lo enuncia. En Doña Inés contra el olvido, don Heliodoro tiene esta función, aquí determinada por la disciplina historiográfica, de regresar el relato dentro del relato de doña Inés, con comentarios que inciden sobre la protagonista y la hacen cambiar el rumbo de la novela. Asimismo,

\footnotetext{
${ }^{10}$ Cf. Lucien Dällenbach, El relato especular, tr. Ramón Buenaventura, Madrid, Visor, 1991, pp. 109 y ss.

${ }^{11}$ Cf. Luis Tamayo, "La invención del psicoanálisis y la formación del psicoanalista”, Acheronta, 22 (2005).
} 
en las reproducciones metadiscursivas a nivel simbólico en el discurso retrospectivo de doña Inés se hace latente el olvido, no como actitud pasiva ante el pasado, sino como su destrucción consciente y su inminente retorno. ${ }^{12} \mathrm{El}$ olvido para el psicoanálisis, como en la mise en abyme, viniendo del pasado se adelanta al futuro y se incluye en su propio proyecto bajo otra forma. En la novela veremos que este mecanismo del olvido no se rompe sino al enfrentar otras versiones de la propia historia. Por tanto, la puesta en abismo trae consigo los elementos conceptuales que articulan la novela; primero la conciencia de la construcción de la propia historia, después las manifestaciones del olvido y la memoria.

\section{Conciencia de la historia}

En la narración de doña Inés abundan las reflexiones sobre el proceso historiográfico al punto de poner la conciencia de la historia en el mismo nivel que los acontecimientos relatados. Aunque esto no significa que la historia refiriéndose a sí misma sea la finalidad de la novela. Si Ana Teresa Torres se vale del recurso metahistórico es solo como punto de partida para representar el proceso consciente de construcción de la propia historia. Desvío de la autorreferencialidad que para Paul Ricoeur representa un compromiso con el conocimiento. En el capítulo sobre "La condición histórica", del libro ya citado, La memoria, la historia, el olvido. Ricoeur habla del historiador como un ser en el mundo, un hombre que es a la vez erudito y ciudadano: "sabio que hace la historia al escribirla, ciudadano que hace la historia en conexión con los demás actores de la escena pública" (395). Se hace presente aquí la relatividad de la historia, determinada tanto por la perspectiva del que habla, cuanto por la temporalidad que condiciona la validez de las ideas. La historia no articula su propio discurso al producirse, porque no es un absoluto nombrándose

\footnotetext{
${ }^{12}$ Cf. Michel de Certeau, Historia y psicoanálisis entre ciencia y ficción, tr. Alfonso
} Mendiola, México, Universidad Iberoamericana, 1995, pp. 77 y ss. 
a sí misma, aunque esto no significa que pueda escribirse historia desde la singularidad del "ahora": la mirada histórica, por definición, necesita de un pasado.

La trama conceptual de la novela no solo se articula por la diferencia de perspectivas, también están muy presentes -yo diría con más peso que la noción de relatividad histórica- las relaciones entre el discurso oficial, legitimante, y el discurso privado, en construcción. El primero cerrado, porque su función lo exige, y el segundo con posibilidad de rehacerse según la situación en que se enuncie. Por ello doña Inés ve pasar la historia oficial sin deshacerla al mismo tiempo que se empeña en vaciar el contenido de su memoria y se permite reconsiderar a lo largo de su narración las valoraciones hechas en un principio.

\subsection{La historia oficial en la mirada de doña Inés}

Sería difícil afirmar que en Doña Inés contra el olvido se deshace el discurso histórico oficial, porque este queda tan arriba y tan lejos de los personajes que no se vuelve relevante ponerlo en crisis al contar la propia historia. Lo explica muy bien Lyotard en "Apostillas a los metarrelatos" de su libro La postmodernidad (explicada a los niños). El discurso oficial está en el metarrelato, o gran relato, de función legitimante, pero la identificación del individuo con este discurso no es obligada. Las historias privadas que traman el tejido de la vida cotidiana se construyen de manera independiente. La distancia de los metarrelatos, respecto a la cotidianidad, se debe a su constitución metafísica que organiza los datos, provenientes del mundo humano o no, en nombres propios. Mismos que para el gran relato funcionan como designadores rígidos, mientras que cualquier relato paralelo puede asignarles frases totalmente heterogéneas. Lo que me interesa remarcar aquí es que el discurso oficial y el privado son visiones simultáneas de la historia. El metarrelato puede ser, y lo es en Doña Inés contra el olvido, un referente indispensable para construir la memoria, no un obstáculo. El propósito de la protagonista es ajustar cuentas con el olvido y la memoria; nunca deshacer la historia oficial para imponer la suya, pues esto sería una manifestación más del olvido. 
La mirada de doña Inés hacia el discurso oficial es de curiosidad y desencanto. Como fantasma tiene facilidad de observar su construcción y el azar, las valoraciones morales, y la repetición cíclica de situaciones son los aspectos que más le intrigan. En el azar está Daria, por ejemplo, que pasa a la historia colectiva sin tener un lugar importante en la sociedad; solo realiza una acción: salvar a la única sucesora de doña Inés. Así valora doña Inés a la esclava: “¿Cómo sabrás tú, negra de dentadura completa, de vientre fértil, negra de veinte años, lo que escribirán de ti?... ¿Cómo sabrás tú el saber de la historia?" (Torres, Doña Inés 67). Del azar se va al caos del mundo del revés en el paso del colonialismo al liberalismo. Nombrar hace la historia y su desorden, observa doña Inés con ironía, en esta sustitución de un nombre por otro: "Ahora a nosotros nos llaman oligarcas y ellos así mismos se llaman liberales. ¿Qué cuál diferencia? No lo sé, Alejandro, no tengo luces para entenderlo" (91). Hay datos que no pueden descodificarse en una línea precisa. Hay movimiento cuyo origen se desconoce. El absurdo parece la única explicación posible en esta visión de conjunto. Estos acontecimientos, para quien los vive, quizá tendrían un sentido moral o ideológico, pero en la recapitulación de doña Inés salta a la vista su falta de lógica:

He visto luchar a los fantasmas de los terratenientes, unos muertos por el gobierno y otros por la oposición, a los antiguos esclavos agrupados en guerrillas para matar a los propietarios, a los propietarios reclutando antiguos esclavos para matar a otros propietarios, a los antiguos esclavos investidos como jefes de ejércitos vagantes y ascendidos a coroneles, a los caudillos populares levantando campesinos sin tierra para matar terratenientes y a los campesinos, convertidos en terratenientes, nombrándose generales para matar a los caudillos populares. He visto incendiar pueblos, iglesias y sabanas, envenenar el agua del ganado, derribar estatuas, morir de cólera y paludismo, dar vivas a los generales y luego pedir su cabeza, alternarse los nombres de conservadores y federales en septenios, quinquenios, bienios, aclamaciones y deposiciones, alzar monumentos y reventarlos, insurgir revoluciones lega- 
listas, continuistas, legitimistas, reivindicadoras, libertadoras y restauradoras, azules, amarillas y de todos los colores, y te repito no he entendido nada. Sólo que abolieron la esclavitud, cuando ya no había esclavos sujetados, porque a esa promesa de la guerra le fueron dando largas hasta mediar el siglo (92).

El ejercicio racional que intenta establecer correspondencias lógicas de causa-efecto trae a cuento las valoraciones morales, de bien y mal, para legitimar la construcción de la historia; pero, como hace notar doña Inés, estas se construyen en el tiempo y en una situación histórica concreta. Prueba de esto es el cambio de benemérito a dictador que se da en la muerte del General Gómez: “la muerte más difícil de nuestra historia" (167). Un gobernante, identificado más tarde como dictador, nunca se autonombró siquiera un mal ciudadano. La serie de hechos que lo vuelven figura negativa se dan en el devenir temporal. Casi siempre demasiado tarde para decírselo de frente: el juego del poder obliga a esperar su muerte para descalificarlo públicamente. Mientras, sus acciones negativas son evidentes, pero se disfrazan de lealtad, justicia, e incluso -como dice doña Inés en este pasaje cargado de ironía- de amor:

Lo lloraron sus ciento diecisiete hijos y sus veintitrés mujeres, lo lloraron sus diez mil caballos y sus cincuenta mil vacas, lo lloraron sus dieciocho haciendas y sus treinta y dos hatos, pero no lo lloró más nadie, porque cuando todo el mundo estuvo seguro de que se había muerto, lo declararon dictador y le quitaron el título de Benemérito (167).

Tal vez entre el azar y las valoraciones morales haya una causalidad oculta, que hace se repita en el tiempo la misma situación con diferentes nombres. El truco del legalismo y la promesa de libertad sirven para ganar hacienda. Los campesinos hambrientos siguen a Joaquín Crespo "como han seguido y seguirán a tantos otros" (108). Hay un móvil ideológico encarnado por figuras atractivas que prometen algún tipo de bienestar -desde dinero hasta la libertad-. Doña Inés observa con una sonrisa amarga a los gobiernos inventados bajo la misma meta de justicia. Con el liberalismo dice: "In- 
ventaron el liberalismo, Alejandro, lo inventó un señor que se llamó Antonio Leocadio Guzmán, hijo de un sargento de granaderos de la Reina, que dio en casarse con la prima del general Bolívar. Y es que el mundo ya no es el mundo y han ocurrido tantos cambios que ya no lo entiendo" (91); después afirma: "No dio resultado el liberalismo, Alejandro, y tuvieron que inventar la dictadura" (107); y al final: "Tampoco dieron resultado las dictaduras y tuvieron que inventar la democracia, Alejandro, se me había olvidado decírtelo. La inventó un señor que se llamó Rómulo Betancourt. ¿Qué si es el mismo que inventó el liberalismo? No, por Dios, ¡qué disparate!, ése fue otro" (183).

\subsection{La bistoria de doña Inés frente al discurso oficial}

Doña Inés se ríe del discurso que construye la historia legitimante pero no puede olvidarlo porque es contrapunto de su historia. Sin el peso de las figuras públicas, asociadas con el poder, no tendría sentido la burla al describir las actividades del burdel La Venus de San Juan, “... otra, de apodo Salomé, gusta de arrodillarlos y jdígame eso!, los hombres a quienes siempre pensé tan dominantes, gustan también de esa humillación" (121); ni tampoco la condena hacia Domingo Sánchez, cuando ofrece a la niña Magdalena como regalo al General a cambio de un favor político.

Domingo Sánchez tiene una consecuencia oculta de sus actos en el adulterio de su esposa Belén. La historia que va tejiendo doña Inés tira de los hilos de manera muy clara; su relato histórico es abiertamente sesgado, porque tiene un propósito que ya está establecido. Ella está contando su verdad y en esa la cara de la historia que le pertenece.

$¿$ Que tienen que haber cambiado mucho las costumbres para que ocurriese ese desafuero? ¿'Te extraña mi relato sin condena? Ay, Alejandro, iqué quieres que te diga! Me siento desconcertada de tantos cambios como han ocurrido, y por momentos pierdo el sentido de las cosas. Yo también me avergüenzo de verla revolcarse en la cama, qué digo en la cama, en el catre de ese turco, y después llegar a su casa con 
una sonrisa de yo no fui ... Ocurre que el pecado de Belén es al mismo tiempo mi venganza. Sí, porque yo detesto a Domingo Sánchez, y detesto su desmemoria. Yo no he podido olvidarme de aquella niña, Magdalena, que dio origen a su ascenso y auge. Los martes de cinco a siete, cuando veo a Belén vestirse y peinarse rápidamente para volver junto a su marido, me digo, vaya la una por la otra. ¿Que le diga al escribano que borre todo este episodio porque te humilla esa desvergonzada? No se puede, Alejandro, lo escrito, escrito queda. Anota escribano: Domingo Sánchez deja saldada su deuda con las mujeres de la casa de San Juan (164).

La cita fue larga, pero la considero buen ejemplo de las líneas de construcción en la historia de doña Inés. Los hechos guardan una extraña relación de causa-efecto, movida por la venganza que compensa deudas con el pasado. El mundo cambia y confunde. Doña Inés sabe que no puede juzgar en ese momento a Belén de la misma forma que lo hubiera hecho un siglo atrás. En este aceptar la sociedad y el discurso oficial fuera del control individual está la imparcialidad de doña Inés, que quiere saldar una deuda siendo fiel a sí misma y a su percepción del mundo. La escritura se da en el tiempo. No hay vuelta atrás en el camino de la reconstrucción de la memoria. Este episodio de Belén es una mancha para su estirpe, pero borrarlo traicionaría su propósito; el compromiso con la memoria tira de ella con más fuerza.

Conviene aquí tener presente otra propuesta de Paul Ricoeur, que a su vez retoma de Carlo Ginzburg: la asociación entre el juez y el historiador. Doña Inés es historiadora al mismo tiempo que defensora de su causa con argumentos y pruebas que remiten al ámbito jurídico; esto conlleva la pretensión de lo real y la línea de la imparcialidad. Aunque se trate de un proyecto imposible, libra al historiador de consignar creaciones de su conciencia. El historiador, como el juez, representa los hechos entre partes adversas, llama a comparecer a testigos y protagonistas; la sentencia que emitirá al final apuntará a la restauración del orden público, será discutida, pero no juzgada de nuevo. Esto explica por qué doña Inés abre el 
discurso a otras voces, que, aun contrarias, la llevan a una conclusión más precisa que si hablara únicamente por su cuenta. Y así no le quedará más remedio que escuchar reproducciones de su historia en boca de Belén y el abogado-historiador don Heliodoro.

\subsection{Apertura a discursos paralelos: Belén y don Heliodoro}

Belén conserva el mito de Daria como patrimonio familiar, lo transmite a sus sobrinos con elementos fantásticos que no estaban en la primera narración de doña Inés. ${ }^{13}$ La protagonista ve en Belén un resquicio de permanencia en el mundo de los vivos. No es alentador que una gran hazaña para la conservación de su linaje sea reducida a una historia para niños, pero es la única posibilidad de rescatar la memoria. Porque además es Belén quien mueve a su sobrino Francisco a buscar a don Heliodoro para recuperar los títulos de posesión de doña Inés.

Don Heliodoro tiene los documentos y la distancia temporal e ideológica que le falta a doña Inés; su discurso, que aboga por la disciplina historiográfica con el rigor del método científico, está fuera del discurso histórico oficial. En él aparece el mismo desencanto que en doña Inés frente a los cambios del mundo. Dice don Heliodoro: "ya yo no añoro nada, pero tampoco creo en nada, yo he visto ya mucho, eso es malo, cuando uno ha visto ya mucho. Lo único que le pedí a la democracia es una beca para esta niña y no me la dio" (193). Este abogado-historiador que presenta en escala el relato de doña Inés organiza los datos de otra manera. La historia ahora suena divertida, casi absurda. La carcajada hacia la vieja mantuana deshace a la protagonista como posible voz de autoridad. Confirmada esta burla por datos que doña Inés no quiso tomar en cuenta: la adulteración que su hijo Nicolás hizo de los títulos de propiedad en 1789; además de otra versión, más pragmática que bondadosa, de la hazaña de la esclava Daria: "y es más probable que se tratara

\footnotetext{
${ }^{13}$ Belén conserva la historia transformándola en mito. Se ocupa de este aspecto Luz Marina Rivas, op. cit., pp. 303 y ss.
} 
de una patraña urdida por la esclava que la presentó en Caracas al padre González, y que quizás pensó de esa manera colocarse en posición de obtener una carta de libertad" (196). Para terminar, don Heliodoro presenta diferentes versiones de la historia de ese litigio por parte de historiadores ficticios; tal vez reproducción ficticia de los textos que Ana Teresa Torres consultó para escribir esta novela. Los documentos, en cuanto signos por descodificarse, son el punto de partida para una narración que les dé sentido, esta a su vez guiada por individuos en una situación histórica específica. Lo más inquietante de la novela es que en cualquiera de las versiones, ya doña Inés, ya don Heliodoro, está la construcción de la historia como fidelidad a la memoria. Ni siquiera en Belén, con su historia para los niños, se asoma la intención de contar un relato de ficción al interior de la novela. Con todo y que en Doña Inés contra el olvido los narradores sean ancianos rayando en la demencia o fantasmas.

En Doña Inés contra el olvido los discursos conviven y los personajes arman su historia sin perder el contacto con el mundo y sin sobreponerse al discurso histórico oficial. Tal vez no se reinvente la historia nacional porque no es dada como noción de pertenencia. Lo que se enseña en la escuela o lo que se dice en los periódicos no les habla de ellos. Por eso la indiferencia de doña Inés frente al paso de la historia, pero su enojo cuando ve un dato de su discurso cuestionado por don Heliodoro:

¿Escuchaste la necedad de don Heliodoro?, que a él no le consta que mi bisnieta Isabel era mi bisnieta. ¿Has consignado, escribano? Un cronólogo vanilocuente observa los títulos de doña Inés y escribe la historia a su manera. Pues sólo me faltaba eso, que tuviera que esperar la aprobación de Heliodoro Chuecos Rincón para estar segura de lo que vieron mis ojos (201).

Falta aquí preguntarse más a fondo por el sentido de la construcción de la historia de doña Inés. No puede asociarse con la transmisión automática de vivencias, que equivaldría a vaciar el contenido de la memoria; también está una lucha contra el olvido como un "peso" que obliga a llevar el pasado a cuestas. 


\section{Entre el olvido y la memoria}

Escoger entre el triunfo de la memoria o el fracaso de la voz individual frente al discurso histórico legitimante parece obligado cuando se llega al final de Doña Inés contra el olvido. Doña Inés no puede modificar la Historia, pierde la voz y regresa a los papeles de donde había salido. Aquí la última imagen de doña Inés:

Mi voz ha perdido peso porque necesitaba de un escribano para hacerla valer y ahora soy devuelta a mi imagen de una vieja mantuana enloquecida, doblado el espinazo, curvas sus uñas como garras, largas y blancas sus sucias guedejas, perdida entre memoriales y sábanas apestosas a orín, llamando a gritos a sus esclavas y a sus hijos que ya la habían olvidado. Vuelvo a donde salí, a mis páginas en las que era un fantasma de papel (237).

Cierto es que el planteamiento inicial de la protagonista no aspiraba más que a eso: volverse un fantasma de papel. Pero al mismo tiempo se deja entrever la capacidad de memoria como fin y valor en sí misma, en cuanto independiente de los resultados obtenidos frente a los otros. La lectura se abre a dos posibilidades, ambas presentes en la novela: la historia de Venezuela, con todo y la valoración ideológica de los venezolanos, o la construcción de la propia historia, sin perder de vista los antecedentes y la situación de la nación a la que se pertenece. La primera conduce inequívocamente al desencanto, la segunda a la valoración de la memoria como liberación. La mayoría de los estudios críticos consultados apuestan por la primera posibilidad -especialmente aquellos que ven en la figura de doña Inés la lucha por rescatar figuras marginales en la disciplina historiográfica-. Es diferente la propuesta de Javier Meneses Linares que da la vuelta del fracaso hacia la liberación del peso del pasado:

La negociación en doña Inés y Juan del Rosario a través de Francisco y José Tomás como salida al conflicto de reconocimiento del otro en dos siglos y medio, sugiere a mi modo de ver no una salida salomónica o una conclusión pesimista, 
como han apuntado algunos críticos. Es un testimonio que convierte a doña Inés en el proceso de libertad (104).

Se encuentra en medio de estas dos posturas Luz Marina Rivas con la atención en la necesidad de historiar lo intrahistórico. El discurso íntimo de doña Inés pone su acento en lo individual; se desdobla entre una voz del ahora y otra de su recuerdo, siempre en la búsqueda de un sentido de pertenencia, frente a la historia oficial, excluyente por definición. ${ }^{14} \mathrm{El}$ reclamo de doña Inés: "en este país de la desmemoria, yo soy puro recuerdo" (Torres, Doña Inés 238) marca el desplazamiento del discurso individual hacia la dimensión simbólica de la voz colectiva. Doña Inés, como fantasma, hace su historia y la oculta para abrir la posibilidad de construcción de otras historias privadas. Más que de la subversión de la historia, se habla del proceso de rememoración que, como se verá a continuación, no puede reducirse a un entusiasta rescate del pasado.

\subsection{Dolor y olvido}

Doña Inés, en su última caracterización, es un fantasma abandonado entre sábanas apestosas a orín que está perdiendo la voz porque ya no tiene oyentes. Cabe preguntarse aquí la función del discurso lanzado desde el abandono y con marcados elementos escatológicos. La mierda, los orines, aparecen al lado de menciones a documentos, cartas, títulos, etc. Junto a los memoriales está la peste a orín: "perdida entre memoriales y sábanas apestosas a orín” (237); la mierda de las ratas, sobre la firma del Rey: "algún día vendrán las ratas y se comerán, golosas, estos fajos de pergamino, de las rendijas del enlosado saldrán espantadas las cucarachas y dejarán la mierda pegada de los bordes, aparecerán por todas partes sus borrones obscuros inconfundibles, y quedará manchada hasta la propia firma del Rey" (12); la mierda evocada con los títulos de posesión, en este

\footnotetext{
${ }^{14}$ Luz Marina Rivas, "El discurso íntimo como discurso historiográfico", op. cit., pp. 169-79.
} 
diálogo oculto: “¿Quieres decirme que yo, como mis títulos, sólo soy una hoja arrebatada por el tiempo y que estoy buscando unos papeles que únicamente servirán para encender el fuego o limpiarme la mierda yo misma, porque las esclavas hace mucho que me han dejado sola?" (13). La evocación desagradable, simbolizada en la mierda, asociada con el rescate de documentos como huellas o pruebas del pasado enterrado, tiene que ver con la dificultad y el dolor del proceso de rememoración. El resultado de los acontecimientos, que puede observar desde el presente, le está en deuda. Parecería que al inicio de la novela condena el olvido de los beneficiados con las tierras de la familia Villegas, pero poco a poco se va descubriendo que el olvido estaba en la misma doña Inés. Acordarse será para ella ajustar cuentas con su historia.

Como ya se dijo, el olvido es acción consciente o inconsciente en contra de los datos percibidos en el pasado, está lleno de huellas escondidas condenadas a repetirse en el futuro. Con olvido de por medio, el movimiento cíclico tiene una causalidad oculta. Paul Ricoeur, en el libro ya citado, aborda el complejo mecanismo del olvido identificando sus diferentes manifestaciones: destrucción de huellas, recuerdo pantalla, obsesión por recordar. Veamos su correspondencia con la novela. Hay olvido como destrucción de huellas, signos que remiten al pasado, en los documentos perdidos de la familia Villegas. Hay olvido como recuerdo reprimido que puede saltar a gritos, en la indignación de doña Inés hacia Juan del Rosario como hijo ilegitimo de su esposo, don Alejandro Martínez de Villegas; historia que el personaje conoció en vida, pero no se atreve a hablarla sino después de muerta. Hay olvido como obsesión por recordar, en el relato sesgado de la protagonista que olvida el fin de Juan del Rosario. Ahora bien, Paul Ricoeur apunta hacia la superación del olvido en el perdón o memoria reconciliada. Equivalente

en la novela a pagar la deuda con el dolor del pasado, es decir, con la ofensa que hizo a doña Inés comenzar su historia.

\subsection{Memoria reconciliada}

El punto más complicado en la propuesta de Ricoeur es la frontera invisible entre el perdón y la amnesia. Queda claro que el olvido al 
ser rescate y liberación no ha de confundirse con el desprendimiento del conocimiento, porque no puede dejarse de lado la noción de pertenencia que necesita la memoria. La frontera entre la memoria reconciliada y la cancelación del pasado estaría en la manera de asumir la memoria -ya como pertenencia, ya como permanencia-.

La narración se abre con una voz ofendida en busca de permanencia. Lo reclama el linaje que garantizaba una vida, sí privilegiada, pero sobre todo estática. La vida de la protagonista ya estaba dada; era una rutina de tiempo y espacio fijos. Pero doña Inés habla cuando ese mundo está perdido. Desde la soledad del fantasma se rompen las certezas de permanencia y entra en juego la indeterminación que se mueve entre la derrota y la posible restitución del orden con ayuda de documentos legitimantes. Sin embargo, el devenir temporal comienza a romper esta aspiración. Lo dice doña Inés en su lamento por la destrucción de Caracas: “¿Que quién se ha muerto? El mundo, se murió el mundo que teníamos. Vivíamos nuestra pequeña aristocracia y tejíamos un mundo que nos parecía eterno" (73). El tiempo destruye, pero también se vuelve para doña Inés posibilidad de venganza al enfrentar el recuerdo del general Joaquín Crespo, enemigo porque expropió sus tierras para el paso del ferrocarril. Ha cambiado la propuesta inicial de la novela, pero sigue la promesa de restauración una vez hallados los títulos de posesión.

La esperanza de recuperar los bienes perdidos se rompe cuando doña Inés se aparta de su historia; la sigue contemplando y es su narradora pero ya no permanece en ella. Aquí se abre el discurso a otras versiones. Belén, en la conservación del mito familiar, y don Heliodoro, en el interés historiográfico. Belén pide a su sobrino Francisco Villaverde que reclame las tierras de la familia con ayuda de don Heliodoro, que ha encontrado los documentos de posesión. Para ese momento los títulos no son más que una curiosidad de anticuario. Aun así está la posibilidad de recuperar el patrimonio perdido durante la Independencia, pero ahora para construir un emporio turístico. Nada más lejano de la intención de doña Inés, motivada por la conservación del linaje y la pureza de sangre. La ruptura de la memoria como permanencia deja escapar los recuerdos que escondía el olvido. Es cuando la protagonista recuerda que 
Juan del Rosario en poco tiempo perdió lo que había robado: "por eso te incluí en el relato, a ti también te quitaron las tierritas" (201); recuerda además que sus títulos no servían de nada. Pero lejos de abandonar el relato, dice a Alejandro que ahora sí puede rescatar lo que le pertenece: "Alejandro, ahora ha llegado el tiempo de recuperar lo que es nuestro ¿Que tú siempre lo creíste tuyo? Sí, Alejandro, porque tú te moriste en paz, pero yo no, yo me morí con el sufrimiento de la historia" (202). La memoria en doña Inés se ha desplazado hacia la noción de pertenencia. Rescatar su pasado se ciñe a saldar una deuda con su olvido.

\subsection{Capacidad de olvido y de memoria}

Ir en contra del olvido no es equivalente a una exaltación de la memoria. Así como el sentido de la memoria cambia en el transcurso de la novela, el olvido tiene diferentes valoraciones. Se deja entrever en la condena de doña Inés a Juan del Rosario un aspecto positivo del olvido. Este personaje, olvidando las obligaciones que le reclamaba su nacimiento, de condición inferior respecto a los mantuanos, se convierte en uno de los emancipadores que fundan la colonia de negros del valle de Curiepe. Doña Inés no acepta que justo con el olvido como liberación, Juan de Rosario le haya ganado la partida: " ¡Y así me pagaste, negro alzado! diciendo que las tierras eran tuyas. ¿Tuyas de qué y de cuándo? No tienes nada, me oyes, nada que yo no te haya dado. Nada que no provenga de mi generosidad y mi poder, negro andrajoso..." (20). Páginas adelante, aparece la temporalidad como balance entre la memoria y el olvido. De manera tajante, doña Inés identifica la memoria con el pasado y el olvido con el futuro, aceptando que no puede oponerse a Juan del Rosario si este tuvo la fuerza suficiente para incidir en el futuro. "Yo tengo la razón que me da el pasado. Tú la que te da el futuro. Ya verás que el tiempo nos cubrirá a los dos completamente" (36).

El tiempo destruye para restablecer el orden. Cualquier valoración definitiva del olvido y la memoria se deshace hacia el final de la novela cuando doña Inés revela que el impulso de su narración era una espera equivocada. La confusión entre pertenencia y per- 
manencia, la liberación del peso del olvido, y al mismo tiempo la conservación del pasado, invalidan la memoria como recuperación o restablecimiento. Aquí doña Inés abre sus reflexiones a la historia de los venezolanos y se une en condiciones a la dimensión simbólica colectiva; ella como todos los demás vivió y se murió esperando una fantasía: "Aquí todo el mundo se ha muerto esperando una promesa, ... a estas alturas las promesas se han revuelto tanto que ya no hay manera de ponerlas en orden y ya no sé si Colón inventó la democracia o Rómulo Betancourt el paraíso terrenal” (229).

La espera equivocada anula la temporalidad que renueva la capacidad de olvido y de memoria. Doña Inés se libra de tener que elegir entre el olvido y la memoria. Lo primero llevaría a la amnesia, siguiendo a Ricoeur, como pérdida de las dimensiones del discurso oficial frente al privado; lo segundo obligaría a amarrarse al pasado. Dijo Paul de Man en 1971: "Es imposible superar la historia en nombre de la vida u olvidar el pasado en nombre de la modernidad, puesto que ambas cosas están vinculadas por una cadena temporal que les confiere un destino común” (167). Desprenderse del pasado sería también cancelar el presente. De aquí la insistencia de Ana Teresa Torres en poner a la literatura entre ficción y pasado histórico. La erosión de la memoria en Venezuela tiene que ver con el discurso legitimante, pero la vuelta hacia el pasado como rescate de la capacidad de memoria no consiste en marcar líneas de presencia obligada. Dicho de otra forma, no es girar la historia hacia los sectores marginados de la población. Volviendo al final de Doña Inés contra el olvido, cabe preguntarse de nuevo por la voz de renuncia que regresa al mundo de los muertos. Tal vez la derrota frente al poder de la historia oficial escondería el triunfo de construir la propia historia. El complejo movimiento del olvido a la memoria y viceversa termina con una cuenta saldada con el pasado. Construir la historia para dejarla ir. 


\section{Obras consultadas}

Bajtín, Mijail M. Problemas de la poética de Dostoievski. Tr. Tatiana Bubnova. México: Fondo de Cultura Económica, 1986.

Britto García, Luis. "La vitrina rota. Narrativa y crisis en la Venezuela contemporánea”. Kohut 37-53.

Casique, Iriada. "La mirada femenina de una historia sin héroes". Texto Crítico 5. 10 (2002): 75-88.

Certeau, Michel de. Historia y psicoanálisis entre ciencia y ficción. Tr. Alfonso Mendiola. México: Universidad Iberoamericana, 1995.

—. La escritura de la historia. Tr. Jorge López Moctezuma. México: Universidad Iberoamericana, 1993.

Dällenbach, Lucien. El relato especular. Tr. Ramón Buenaventura. Madrid: Visor, 1991.

Dimo, Edith y Amarilis Hidalgo de Jesús, eds. Escritura y desafí: narradoras venezolanas del siglo XX. Caracas: Monte Ávila, 1996.

Franco, Fabiola. "Mujer historia e identidad en Hispanoamérica: Doña Inés contra el olvido de Ana Teresa Torres". Revista de Literatura Hispanoamericana 35 (1997): 63-73.

González Stephan, Beatriz. "La resistencia de la memoria: una escritura contra el poder del olvido". Kohut 115-126.

Kohut, Karl, ed. Literatura venezolana boy. Historia nacional y presente urbano. Frankfurt-Madrid: Vervuert; Iberoamericana, 1999.

Lyotard, Jean-Fançois. La postmodernidad (explicada a los niños). Tr. Enrique Lynch. Barcelona: Gedisa, 1994.

Man, Paul de. "Historia literaria y modernidad literaria". Tr. Hugo Rodríguez Vecchi y Jacques Legra. Visión y Ceguera. Puerto Rico: Ed. de la Universidad, 1991.

Meneses Linares, Javier. "La deconstrucción del tiempo de la historia a través de la ficción en la novela Doña Inés contra el olvido de Ana Teresa Torres". Revista de Literatura Hispanoamericana 48 (2004): 93-105.

Pacheco, Carlos. "Textos en la frontera: autobiografía, ficción y escritura de mujeres". Kohut 127-37.

Ricoeur, Paul. La memoria, la historia, el olvido. Tr. Agustín Neira. Buenos Aires: Fondo de Cultura Económica de Argentina, 2004. 
Rivas, Luz Marina. La novela intrahistórica. Tres miradas femeninas de la historia venezolana. Mérida, Venezuela: Eds. El otro el mismo, 2004.

Tamayo, Luis. "La invención del psicoanálisis y la formación del psicoanalista". Acheronta 22 (2005).

Tompkins, Cynthia. "La re-escritura de la historia en Doña Inés contra el olvido de Ana Teresa Torres”. Dimo e Hidalgo de Jesús 103-23.

Torres, Ana Teresa. Doña Inés contra el olvido. Caracas: Monte Ávila, 1992.

- "Literatura y país: reflexiones sobre sus relaciones". Kohut 55-65. 